\title{
BIOÉTICA E BIODIREITO: AS IMPLICAÇÕES DE UM REENCONTRO
}

\author{
Reinaldo Pereira e Silva*
}

\begin{abstract}
Resumo: Este estudo tem por objeto de investigação o estatuto da vida humana desde a concepção, encontrando justificação na complexa crise político-jurídica atual, documentada de forma particularmente emblemática pela atitude omissa das legislações, inclusive a brasileira, em face das inovações tecnológicas no âmbito biomédico. O objetivo geral é demonstrar que, muito embora os conhecimentos nas áreas da embriologia clínica e da genética médica dissipem quaisquer dúvidas sobre o início da individualidade humana, as reflexões ética e jurídica, quando assentadas em premissas discordantes com a "natureza humana", obscurecem a qualidade de pessoa que o ser humano expressa desde sua concepção. Em outras palavras, o objetivo geral se envolve com a demonstração de que somente se pode falar em direito e em ética, para muito além das abordagens vazias de conteúdo, quando se orienta a projeção reflexiva em conformidade com a natureza humana.
\end{abstract}

Palavras chave: Bioética, biodireito, estatuto da vida, teoria da cariogamia, princípio da dignidade da pessoa humana

\section{BIOÉTICA Y BIODERECHO: LAS IMPLICACIONES DE UN REENCUENTRO}

Resumen: Este estudio tiene por objeto de investigación el estatuto de la vida humana desde la concepción, encontrando justificación en la compleja crisis político-jurídica actual, representada de manera particularmente emblemática por la actitud omisiva de las legislaciones, incluida la brasileña, en relación con las innovaciones tecnológicas en el ámbito biomédico. El objetivo general es demostrar que, aunque los conocimientos en las áreas de embriología clínica y de genética médica disipan cualquier duda sobre el inicio de la individualidad humana, las reflexiones ética y jurídica, cuando se basan en premisas discordantes con la "naturaleza humana", oscurecen la calidad de persona que el ser humano posee desde la concepción. En otras palabras, el objetivo general dice relación con la demostración de que sólo se puede hablar en derecho y en ética, más allá de aproximaciones carentes de contenido, cuando la reflexión se orienta en un sentido concordante con la naturaleza humana.

Palabras clave: Bioética, bioderecho, estatuto de la vida, teoría de la cariogamia, principio de dignidad de la persona humana

\section{BIOETHICS AND BIOLAW: IMPLICATIONS OF A REENCOUNTER}

\begin{abstract}
The purpose of this study is to investigate the statute of human life from conception on, finding a justification in the current complex political-juridical crisis, documented in a particularly emblematic way in the negligent attitude of legislation, including Brasilian legislation, in view of the technological innovations in the biomedical domain. The general aim is to demonstrate that, even though knowledge in the areas of clinical embryology and medical genetics dispel any doubts regarding the beginning of human individuality, ethical and juridical reflections, when based on premises that are discordant with "human nature", darkening obscure the personal quality the human being expresses from the time of his conception. In other words, the general aim is related with the demonstration that one can only talk about law and ethics, going beyond approaches devoid of content, when he is oriented towards a reflective attitude in accordance with human nature.
\end{abstract}

Key words: Bioethic, biolaw, statute of life, theory of karygamy, principle of human dignity

\footnotetext{
* Doutor em Direito. Professor de Direito Constitucional e Teoria Geral do Direito Civil na Universidade Federal de Santa Catarina. Membro Efetivo da Comissão Nacional de Direitos Humanos do Conselho Federal da Ordem dos Advogados do Brasil - CNDH e da Sociedade Brasileira de Bioética - SBB.

Correspondencia: reinaldopereiraesilva@uol.com.br
} 


\section{Introdução}

A análise das implicações do reencontro do direito com a ética pretende demonstrar a possibilidade de compreensão do fenômeno humano ainda que num contexto em que a tecnociência - que nada mais é do que o conhecimento de caráter positivista levado a seu extremo - não mais permite distinguir a ciência (conhecimento puro) da tecnologia (conhecimento aplicado) ${ }^{1}$. A transformação despudorada da sociedade em um grande laboratório, a sujeição atual de todos os homens à condição de consumidores/cobaias dos implementos tecnocientíficos, ocorre porque a tecnociência não consegue diferenciar pessoas de coisas, haja vista que ela não conhece senão as coisas, que são objetos por ela mesma constituídos $^{2}$. Respaldada pelos interesses de um mercado econômico globalizado, ela não ascende ao ser dos fenômenos porque não lhe interessa apreender senão os fenômenos do ser. No entanto, a tecnociência impõe sua compreensão mecanicista não apenas aos fenômenos do ser, mas também ao ser dos fenômenos, notadamente do fenômeno humano, o que resulta considerar a vida, ao revés de um valor fundamental, uma soma dos valores de utilidade de seus órgãos. Ora, a vida, para não perder o status de fundamento da dignidade da pessoa humana ${ }^{3}$, não pode ser explicada pela

\footnotetext{
1 Para aprofundar o conceito de tecnociência, consultar Pessini L, Barchifontaine CdeP. Problemas atuais de bioética. São Paulo: Loyola \& Centro Universitário São Camilo; 2000: $65-$ 9. También Silva RP. Reflexões ecológico-jurídicas sobre o biodireito. Revista dos Tribunais 2001. São Paulo: 90 (791) 99-102.

2 É o império da "irresponsabilidade organizada" de que fala Ulrich Beck, lembrando que, na sociedade de risco (société $d u$ risque), substituta moderna da sociedade industrial e de sua lógica, a espécie humana se torna cobaia em um laboratório onde ninguém se responsabilidade pelo resultado das experiências. Cf. entrevista concedida a Reverchon A. Allo la Terre? Ici la nouvelle planète des risques. Le Monde Economie. Paris, 20 nov. 2001

Se é verdade que a vida física, pela qual tem início a caminhada humana no mundo, não representa um bem supremo, ela é sem dúvida alguma um valor fundamental porque garante o desenvolvimento dos demais valores que conferem dignidade à pessoa humana.
}

ótica do mecanicismo, porque a causalidade mecânica não obtém outro efeito que não seja um reagrupamento de elementos que não se modificam, muito embora se modifique o espaço. A vida, ao contrário, cria o espaço, porque não recebe simplesmente seu conteúdo do espaço, mas nele insere, com o tempo, algo ainda não presente( $1-3)$. Nesse sentido, para que se possa falar seriamente de uma ética e de um direito da vida, o fenômeno humano deve ser entendido como uma forma especial de temporalidade, que é a duração, já que transforma a sucessão cronológica de seu desenvolvimento natural em sucessão existencial de eventos dotados de sentido. $\mathrm{O}$ respeito que é devido à dignidade humana, como a mais conseqüente implicação do reencontro do direito com a ética, ampara-se então em dois desdobramentos da idéia de duração: 1) todos os integrantes da espécie humana devem ser igualmente respeitados; e 2) o respeito deve ser assegurado independentemente do grau de desenvolvimento individual das potencialidades humanas, isto é, desde a concepção, ainda que extra-uterina, até a fase adulta. Somente afastando-se das limitações mecanicistas da tecnociência é possível afirmar que todo ser humano é pessoa e possui direitos que emanam de sua própria natureza.

\section{A vida como fundamento da dignidade}

Assim como a responsabilidade pela própria vida, o dever de ajudar a viver quando o outro ainda não tem, ou não mais tem, capacidade de fazê-lo por si mesmo, não é uma imposição heterônoma, um dever imposto de fora, mas uma resposta a algo que diz respeito à natureza de cada homem e de todos os homens ${ }^{4}$. Esclarece Erich Fromm que responsabilidade e

\footnotetext{
4 "Um indivíduo fechado, isolado do outro, não realiza sua autonomia, fica alienado. Porém, um excesso de vínculo com o outro, uma relação com o outro sem movimento próprio, também conduz à alienação. A autonomia é um vínculo com o outro em que ambos têm movimento próprio" (Warat LA. $A$ ciência jurídica e seus dois maridos. Santa Cruz do Sul: Edunisc; 2000: 125)
} 
resposta têm a mesma raiz, respondere. Ser responsável significa, portanto, estar disposto a responder ${ }^{5}$. Em termos de pensamento forte, a vida é considera o fundamento da dignidade da pessoa humana na exata medida em que cada homem está disposto a responder às demandas de sua natureza ${ }^{6}$. O avesso disto é a irresponsabilidade, a justificação de tudo por parte de todos, o chamado "pensamento fraco" (pensiero debole)(1, p. 78-80). No amplo domínio do que se denomina reflexão bioética, há variadas formas de manifestação do pensamento fraco. Basta analisar as diversas teorias que discorrem sobre o alvorecer da vida para constatar a debilidade de suas premissas, já que muitas delas não possuem qualquer compromisso com a natureza humana. Com efeito, diversas são as teorias, com pretensão de cientificidade, que defendem critérios para a identificação do início da vida humana sem qualquer respaldo ontológico. Em outras palavras, são teorias que não ascendem ao ser dos fenômenos porque se lhes bastam os fenômenos do ser. As teorias dotadas dos argumentos mais frágeis, porque estranhas ao confronto de suas premissas com as novas descobertas biomédicas, são a da natalidade e da gestação. A primeira advoga que a existência humana se firma a partir do nascimento com vida (somando-se, ou não, constatações como a viabilidade e a conformação humana) e a segunda postula que a existência humana se firma gradualmente, relacionando sua completude ao tempo gestacional ${ }^{7}$.

\footnotetext{
5 Fromm E. Ética y psicoanálisis. México: Fondo de Cultura Económica; 1998: 113. "O conceito de pessoa em sentido ético inclui a idéia de responsabilidade. Trata-se de um fenômeno básico da existência humana que é indiscutível como fato experimentável da consciência, qualquer que seja a interpretação metafísica que se possa dar. Ter responsabilidade é um privilégio e uma carga da pessoa" (Larenz K. Derecho civil. Parte general. Madrid: Edersa; 1978: 50).

6 “O serviço a favor da vida deve ser unitário: não pode tolerar discriminações, já que a vida humana é inviolável em todas as suas fases e situações; é um bem indivisível. Trata-se de cuidar da vida toda e da vida de todos" (João Paulo II. Evangelium Vitae, 87).

A respeito da teoria que relaciona a aquisição da individualidade humana ao tempo gestacional, Mori M. A moralidade do aborto. Brasília: UnB; 1997: 55-6.
}

A teoria da natalidade é expressão de certa doutrina romana segundo a qual o concepto, nas entranhas maternas, não possui individualidade alguma, sendo apenas uma parte da mulher (partus enim antequam edatur, mulieris portio est vel viscerum) ${ }^{8}$. Esta teoria, apesar de rechaçada pelas descobertas no campo da embriologia humana, ainda é culturalmente muito influente. Muitos teóricos vinculados à chamada "moralidade secular" a ela recorrem freqüentemente, posto que não a explicitem; outros tantos, quando a explicitam, argumentam para muito além de suas premissas. H. Tristram Engelhardt Jr., exemplo desta segunda orientação no manuseio da teoria da natalidade, defende que os zigotos, os embriões e os fetos, da mesma forma que "as crianças pequenas", porque "produtos da engenhosidade e das energias das pessoas, podem ser considerados posses"; em conseqüência, "podem ser comprados e vendidos como se não passassem de coisas" ". A argumentação de H. Tristram Engelhardt Jr. é bastante representativa das implicações da teoria da natalidade, mormente quando pontua que o mais importante na investigação ética não é a pertinência do homem à espécie homo sapiens e sim o fato de se tornar pessoa, o que ocorre mediante o ingresso na chamada "comunidade moral". Antes disso, os zigotos, os embriões e os fetos (além dos bebês, dos deficientes mentais e daqueles que

8 Em defesa da teoria natalista no direito romano, Cretella Júnior J. Curso de direito romano. Rio de Janeiro: Forense; 2000: 62. Trabucchi A. Instituciones de derecho civil. Madrid: Editorial Revista del Derecho Privado; 1967: 79. Salvat RM. Tratado de derecho civil argentino. Tomo I Buenos Aires: Editora Argentina; 1954: 244-5. Da Silva Pereira CM. Instituições de direito civil Tomo I. Rio de Janeiro: Forense; 1996: 144. Dias JA. Procriação assistida e responsabilidade médica. Coimbra: Coimbra Editora; 1996: 177-80. Messina de Estrella Gutiérrez GN. Bioderecho. Buenos Aires: AbeledoPerrot; 1998: 46. Em defesa da teoria concepcionista no direito romano, com fundamento nas pesquisas, dentre outros, de Almeida SCh e. Tutela civil do nascituro. São Paulo: Saraiva, 2000: 41-7.

9 Engelhardt HT. Fundamentos da bioética. São Paulo: Loyola; 1998: 199, 310. "Zigotos, embriões e fetos produzidos em particular são considerados propriedade particular; seriam propriedade da sociedade apenas se cooperativas os produzissem". 
sofrem do mal de Alzheimer, por exemplo) não são senão "objeto de beneficência". Nesse sentido, "somente aquelas entidades que podem consentir em algo, que podem transmitir autoridade moral em relação a elas mesmas e a suas posses são denominadas pessoas". Em conseqüência dessa concepção discriminatória, existem dois tipos de seres humanos, o indivíduo humano/pessoa (ser reflexivo e manipulador) e o indivíduo humano/não pessoa (objeto de reflexão e manipulação). Fácil constatar que o grande erro da teoria de $\mathrm{H}$. Tristram Engelhardt Jr. consiste em não reconhecer valor intrínseco ao homem, mas apenas um valor convencionado pela "comunidade moral". Ora, a convenção concernente ao "indivíduo humano/não pessoa" repousa na confusão entre igualdade e identidade. Dizer que os homens são iguais não significa dizer que sejam idênticos. Quando se fala de igualdade se quer afirmar que todos os homens têm o mesmo valor, a mesma dignidade em razão de sua qualidade de pessoa. Todavia, a própria idéia de pessoa implica a idéia de singularidade, de diferença. Se se reconhece a igualdade entre os homens, isto significa que, sejam quais forem as diferenças físicas ou intelectuais que se observem, todos têm o mesmo valor e são iguais em dignidade. Na verdade, "as pessoas têm o direito a ser iguais quando a diferença as inferioriza, e o direito a ser diferentes quando a igualdade as descaracteriza"(4).

Também goza de grande prestígio cultural, apesar de cientificamente débil, a teoria da gestação. Um exemplo de consagração histórica da teoria da "gestação" é o caso "Roe versus Wade", decidido em 22 de janeiro de 1973 pela Suprema Corte norte-americana, oportunidade em que se declarou a inconstitucionalidade de uma lei texana que descrevia, de maneira ampla, o crime de abortamento. Fundada na $14^{\mathrm{a}}$ Emenda, que tutela a intimidade (privacy), a decisão suprema reconheceu à mãe o direto incondicional de optar entre o abortamento e a gestação nos primeiros três meses, posto que resguardando o critério da saúde materna, também para efeito de abortamento, até o sexto mês. Nesse contexto, a preocupação com a existência do concepto, autorizando a intervenção estatal para sua tutela, somente se admitiu após os seis meses de gestação(5), sob a justificativa da "viabilidade", pois, desde então, "supõe-se que o feto tenha a capacidade de levar uma vida significativa fora do útero materno"(6). A teoria da gestação, quando assume pretensos rigores científicos, ora se fundamenta em argumentos monofatoriais, ora se alicerça em argumentos multifatoriais. Exemplos do primeiro caso são os critérios da atividade unificante do sistema nervoso central, da presença do aspecto humano ou da capacidade de sentir a dor física, que fracionam a gestação, bem como a existência do ser humano, em períodos temporais fechados. No segundo caso, todos os critérios aludidos devem se fazer presentes simultaneamente, em dado tempo gestacional, não se identificando antes disso o início da existência humana. Nesta perspectiva a existência humana deixa de ser uma constatação de natureza substancial e assume o caráter de um cálculo matemático: o indivíduo humano se identifica com uma soma de atividades e características. O valor igual de cada existência humana, independente do estágio de seu desenvolvimento, perde sentido e os acentos acidentais e qualidades secundárias são alçados ao status de critérios capazes de identificar a individualidade, a despeito da essência do ser humano ${ }^{10}$. As perigosas implicações da teoria da gestação são bastante evidentes, porque, se a existência humana se reduz à verificação de uma específica atividade ou característica humana, ou de diversas atividades/características, torna-se justificada a discriminação dos seres humanos com base na verificação ou não destas mesmas atividades ou características humanas(7).

\footnotetext{
10 "Em tudo aquilo que é resultado da natureza humana, adquirese primeiro a capacidade e depois produz-se a operação (por exemplo, no caso dos sentidos, os homens não adquirem os sentidos por ver ou ouvir muitas vezes, senão o inverso: os homens os usam porque os têm, não os têm por usá-los)" (Aritóteles. Ética a Nicómaco. Madrid: Centro de estudios políticos y constitucionales; 1999: 19).
} 
Outras teorias que discorrem sobre o alvorecer da vida humana são a da singamia, a da cariogamia e a do pré-embrião. Para esclarecer as duas primeiras ${ }^{11}$, é importante relembrar que entre a fertilização do óvulo e a concepção costuma decorrer um período de tempo de aproximadamente 12 (doze) horas. Em defesa da teoria da singamia, Roberto Andorno entende que alguns estudiosos, socorrendo-se de argumentos que ele considera inadequados, têm pretendido retardar o conceito de 'concepção' ao momento em que ocorre a fusão dos pronúcleos dos gametas masculino e feminino (cariogamia). Daí porque advoga que desde o momento da penetração do espermatozóide no óvulo se inicia o "processo irreversível" de concepção de um novo ser humano, isto é, desde a fusão das membranas dos gametas masculino e feminino. Para a teoria da singamia, antes mesmo da cariogamia, uma série de reações em cadeia garante o que se pode denominar de processo de individualização/personalização do homem(8-15). Assim, a teoria da singamia distingue-se da teoria da cariogamia na medida em que admite o primórdio da individualidade humana antes da concepção, isto é, no exato momento da fertilização, que ocorre quando apenas um, de aproximadamente duzentos a seiscentos milhões de espermatozóides liberados na ejaculação, consegue atravessar a zona pelúcida do óvulo, após passar através da corona radiata, constituída por camadas de células foliculares que igualmente circundam o óvulo. Muito embora a teoria da singamia também participe das chamadas doutrinas "concepcionistas", na teoria da cariogamia o conceito de "concepção" é bem mais específico, já que apenas reconhece o início da

\footnotetext{
${ }^{11}$ A singamia, também denominada anfimixia, é o evento que corresponde à união dos gametas masculino e feminino. A cariogamia, evento sucessivo, corresponde à fusão dos cariogametas, isto é, os pronúcleos masculino e feminino. Consultar, para maior aprofundamento, Pietro MLdi. Estatuto ontológico do embrião humano. In: Cinà $\mathrm{G}$, et alli, org. Dicionário interdisciplinar da Pastoral da Saúde. São Paulo: Paulus; 1999: 427-9.
}

existência humana após a fusão dos pronúcleos masculino e feminino no interior do ovo. Dessa maneira, a teoria da cariogamia defende que desde a concepção, entendida como a fusão dos pronúcleos dos gametas masculino e feminino, o que já existe é uma vida humana em ato, isto é, um indivíduo humano dotado de potencialidade. Rechaça-se, assim, a fórmula do Comitê Consultivo Francês de Ética (Comité Consultatif d'Éthique Français) segundo a qual o zigoto é um indivíduo humano potencial, ou pura potência de humanidade(16). Ao final, é necessário alertar para o fato de a teoria do pré-embrião distinguir-se das duas anteriores na medida em que compreende, a exemplo da teoria da gestação, a existência humana artificialmente fracionada, escorando-se em argumentos monofatoriais para justificá-la apenas a partir do $14^{\circ}$ dia após a concepção. Diferentemente da teoria da gestação, a teoria do pré-embrião prescinde da ocorrência da gestação para fundar suas implicações.

\section{A teoria do pré-embrião}

O chamado critério do $14^{\circ}$ dia, contido, originalmente, em um documento intitulado Informe Warnock sobre Fertilização e Embriologia (Inquiry Warnock into Human Fertilisation and Embryology)(17), publicado no Reino Unido em 1984, no âmbito do chamado Warnock Committee, e depois presente em outros documentos governamentais, como o relatório Waller, do estado de Vitória, na Austrália, também de 1984(17, p 128-9), e o Informe Palacios, publicado na Espanha em $1986^{12}$, está embasado na teoria do pré-embrião ou do "embrião precoce", sendo que suas motivações não comparecem em nenhum tratado de biologia, mas na literatura dedicada às tecnologias da infertilidade. A principal tese

\footnotetext{
${ }^{12}$ O Informe Palacios, de 6 de março de 1986, foi elaborada pela Comissão Especial de Estudos da Fertilização in vitro e da Inseminação Artificial Humanas, presidida por Marcelo Palacios Alons. A respeito, Mateo RM. Bioética y derecho. Barcelona: Ariel; 1987: 145.
} 
dessa teoria é que o zigoto humano, ainda que expressão da natureza humana, não é um indivíduo humano em ato, mas apenas uma célula progenitora humana dotada da potencialidade para gerar um ou mais indivíduos da espécie humana. Sujeito às demandas do mercado econômico globalizado, o estatuto da vida é então relativizado. Trata-se de uma postura manifestamente ideológica, haja vista que promove a subordinação inconfessa de uma posição teórica a uma postura prática, não tendo outro objetivo senão legitimar a manipulação de seres humanos(18-21). Mary Warnock, em manifesta defesa da manipulação de seres humanos, chega a argumentar que, "uma vez que não há qualquer indivíduo sendo sacrificado, a utilização de 'embriões precoces' para pesquisa é passível de ser justificada"(22). A idéia de duração, exposta na introdução deste estudo, é também expressamente rechaçada pela teoria do pré-embrião. Recorrendo-se à doutrina de Pierre Teilhard de Chardin, podese classificar tal teoria de pré-moderna, porque 'o que faz um homem 'moderno', e como tal o classifica ( $\mathrm{e}$, nesse sentido, uma multidão de contemporâneos não são ainda modernos), é terse tornado capaz de ver, não só no espaço, não só no tempo, mas igualmente na duração ${ }^{13}$; e é também, além disso, achar-se incapaz de nada ver de outra maneira - nada - a começar por ele próprio"(23). Em sendo "a duração um fluido contínuo sem partes separáveis", impossível segmentar no ciclo vital do homem estágios que não participem da mesma natureza humana. Desse modo, a definição de pré-embrião, cuja defesa por Mary Warnock motiva a objeção à idéia de duração, repousa no pressuposto de que antes do advento do humano existe uma realidade pré-humana no universo de "uma série sucessiva de maneiras de ser de um ser único". Se "a vida não opera por intermitências, ela empurra para diante toda sua trama ao mesmo tempo"(23, p.176). Muitas, entretanto, são as motivações que visam a justificar o

13 "Ou, o que vem a dar no mesmo, no espaço-tempo biológico". critério do $14^{\circ}$ dia, que alguns também identificam com o critério da nidação(24). Dentre elas, destacam-se: a) após o $14^{\circ}$ dia não é mais possível a formação de gêmeos monozigóticos; b) somente após o $14^{\circ}$ dia o concepto perde a qualidade de totipotência; e c) em torno do $14^{\circ}$ dia aparece a linha primitiva no concepto, como que o signo de um novo ser humano(22, p.35-52)(25-27). Expor-se-ão todas as motivações, na seqüência apresentada, com as correspondentes argumentações, para somente após, de maneira conclusiva, criticálas.

No que diz respeito à geração de gêmeos monozigóticos (a), é importante ressaltar que ainda não são conhecidas as causas naturais da cisão gemelar. Ora se defende a predisposição genética, ora apontam-se os fatores ambientais. Artificialmente, a cisão gemelar pode ser realizada por micromanipulação no zigoto e nas primeiras células decorrentes de sua clivagem. Dessa forma, para a teoria do pré-embrião, enquanto for possível a geração de gêmeos monozigóticos, não há que se falar em individualidade humana. Norman Ford exemplifica a tese: suponha-se que o zigoto originário, de nome João, tenha conservado a própria individualidade no curso do processo de geração de um outro indivíduo geneticamente idêntico, de nome Pedro. Com a cisão gemelar, João se reduz pela metade, ficando João e Pedro com a mesma identidade genética. $\mathrm{O}$ problema que se apresenta está na impossibilidade de estabelecer critérios objetivos que permitam, após a cisão gemelar, dizer qual dos dois é João. Assim, para a teoria do pré-embrião, antes do $14^{\circ}$ dia após a concepção não se pode falar em continuidade ininterrupta de uma mesma vida humana. A possibilidade da cisão gemelar representa uma fratura na aludida continuidade, impondo a conclusão que "o zigoto é um indivíduo humano em potência, mas não um indivíduo humano em ato"(6, p.166-7)(25, p.184-90). Além disso, somente após o $14^{\circ}$ dia, a contar da concepção humana, há perda da qualidade celular de totipotência 
(b). Escorada neste dado, a teoria do préembrião também entende que não se pode falar em individualidade genética enquanto a totipotência, que caracteriza o zigoto e as primeiras células decorrentes de sua clivagem, não for superada pela especialização. Isto porque, antes de definidas as células que formarão o embrião propriamente dito, ou os embriões monozigóticos, e as células que se destinarão às estruturas extra-embrionárias, que servem às necessidades de seu desenvolvimento, não é possível falar em vida humana em ato. Para a teoria do pré-embrião, somado à possibilidade da cisão gemelar, o período de indiferenciação celular veda o reconhecimento da individualidade humana. Nesse sentido, é necessária significativa multiplicação celular e vários dias após a concepção para que a individualidade biológica seja determinada. A perda da totipotência assinala que a potencialidade se torna restrita precisamente porque intervém a individualização espécieespecífica, isto é, porque já está formado um indivíduo pluricelular distinto. Uma vez formado o indivíduo humano em ato, não há mais razão para a potencialidade para gerar um ou mais indivíduos(25, p.241-2). Por fim, também é mister lembrar que a partir da fertilização pode ocorrer a não potencialização de um indivíduo humano, mas uma formação tumoral como o coriocarcinoma. Desta maneira, somente a partir do $14^{\circ}$ dia após a concepção, com o aparecimento da linha primitiva (c) que assegura a organização espacial da simetria humana, a teoria do pré-embrião considera possível afirmar o início de uma vida biológica em desenvolvimento(28). Em outras palavras, quando as células do epiblasto, graças à linha primitiva, organizam uma estrutura corpórea de simetria bilateral definitiva, há a formação de um indivíduo humano, já que este não pode existir sem um corpo humano definitivo. Depois do estágio da linha primitiva, a possibilidade da cisão gemelar é praticamente nula, em razão da geração de um indivíduo em ato e porque não há mais células capazes de gerar outros indivíduos. Para a teoria do pré-embrião, "nas vicissitudes das duas primeiras semanas que se seguem à concepção se deve ver não o desenvolvimento do ser humano, mas um processo de síntese da individualidade, pois, até o aparecimento da linha primitiva, as células, multiplicando-se, não fazem outra coisa senão sintetizar um indivíduo humano"(25, p.250-65).

\section{A teoria da cariogamia}

Para este estudo, a teoria que melhor esclarece o alvorecer da vida humana é a da cariogamia ${ }^{14}$. Com efeito, a concepção, que é o início do desenrolar de toda a jornada do homem, é precedida pela fertilização, que ocorre quando apenas um, de aproximadamente duzentos a seiscentos milhões de espermatozóides liberados na ejaculação, consegue atravessar a zona pelúcida do óvu$10^{15}$. Não se sabe ao certo quanto tempo os

\footnotetext{
${ }_{14}$ A maior parte da doutrina especializada utiliza erroneamente o conceito de singamia para definir o fenômeno da cariogamia. O relatório 15/CNECV/95, do Conselho Português de Ética para as Ciências da Vida, por exemplo, assevera, no seu item 10, que "o princípio de uma nova vida humana é a singamia, ou seja, a fusão dos dois pronúcleos (de origem materna e de origem paterna), e não a penetraçào do espermatozóide no óvulo". No mesmo errôneo sentido, Zegers Hochschild F. Reflexiones sobre los inicios del individuo humano [Sitio en Internet] Disponible en: http://www.uchile.cl/bioetica/doc/ refini.htm Acceso en out 2002. Honnefelder L. Naturaleza y status del embrión. Aspectos filosoficos. Cuadernos de bioetica Madrid 1997; VIII; 31: 1045-6. Lobato A. Os direitos humanos e o direito à vida: por uma carta dos direitos do embrião. In: Ladusãns $\mathrm{S}$, org. Questões atuais de bioética. São Paulo: Loyola; 1990: 353. Monge F. Persona humana y procreación artificial. Madrid: MC; 1988: 43. Pérez B. Personalidad del nasciturus extracorporis. Periódico Salteño Independente [Sitio en nternet] Disponible en: http:// www.iruya.com/ent/claves/perez.htm. Acceso em out. 2002. Rager G. Embrion-hombre-persona. Acerca de la cuestion del comienzo de la vida personal. Cuadernos de bioetica Madrid 1997; VIII; 31: 1049. Serra A. Chi o che cosa è l'embrione umano? I dati della scienza. In: Sgreccia E, Pietro Mldi, org. Bioetica ed educazione. Milano: Editrice La Scuola; 1997: 140-2. Siqueira Mde. O início da vida e a medicina atual. In: Penteado JdeC et alli, org. A vida dos direitos humanos. Bioética médica e bioética jurídica. Porto Alegre: Sérgio Fabris Editor; 1999: 337-45. Testart J. O ovo transparente. São Paulo: Edusp; 1995: 76.

15 Antes de o espermatozóide penetrar na zona pelúcida, conforme acima descrito, ele passa através da corona radiata, constituída por camadas de células foliculares que circundam o óvulo.
} 
espermatozóides levam para atingir o sítio de fertilização. Calcula-se que o tempo de transporte varie entre 5 (cinco) e 45 (quarenta e cinco) minutos. No óvulo, que passa a se chamar ovo após a fertilização, desencadeiam-se duas importantes reações: uma imediata, na zona pelúcida, que impede a penetração de mais de um espermatozóide; e outra mediata, na estrutura metabólica do ovo, constituindo o ponto de partida da embriogênese ${ }^{16}$. Ao mesmo tempo em que a reação de zona se desdobra, ocorre a fusão das membranas plasmáticas do óvulo e do espermatozóide, assegurando que a cabeça, o colo e a cauda deste, liberados de sua membrana, ingressem no citoplasma daquele. Em seguida, no centro do ovo, o dote genético materno organiza-se em uma etapa denominada pronúcleo. Também o dote genético paterno constante da cabeça do espermatozóide, após desembaraçar-se de seus colo e cauda, que se degeneram no citoplasma do ovo, migra para o centro deste, organizando-se em pronúcleo. Ali os pronúcleos ficam lado a lado, cada qual circundado por uma membrana nuclear, e o paterno incha até alcançar o tamanho do materno. Os gametas masculino e feminino, porque são células da linhagem germinativa, possuem o complemento haplóide ou n (23 cromossomos). Quando os pronúcleos materno e paterno se aproximam, perdem suas membranas e se fundem, compondo o complemento diplóide ou $2 \mathrm{n}$ (46 cromossomos) do zigoto, é que se deve falar da concepção de um novo ser humano(21, p.7)(29,30). Sabendo-se que do momento do encontro do espermatozóide com o óvulo até a geração do zigoto transcorre um período de tempo de aproximadamente 12 (doze) horas, apenas após esse período é que se deve falar da concepção de uma vida humana geneticamente distinta da dos genitores(5, p. 371-2). Eis aqui

\footnotetext{
16 “A fertilização causa a ativação metabólica do óvulo, necessária para que ocorra a clivagem e o desenvolvimento embrionário subseqüente". (Carlson BM. Embriologia humana e biologia do desenvolvimento. São Paulo: Guanabara Koogan; 1996: 29). Cf. também, Testart J. O ovo transparente. São Paulo: Edusp; 1995: 85 .
}

a grande diferença em relação à teoria da singamia. Em suma, a cariogamia consiste na dissolução das membranas que cobrem os pronúcleos, permitindo a fusão da informação genética contida em duas parcialidades com identidades diferentes para formar um todo novo ${ }^{17}$.

Angelo Serra fundamenta a teoria da cariogamia em quatro argumentos cientificamente comprovados: a) a fusão dos pronúcleos materno e paterno inicia a existência uma nova célula somática dotada de uma tal estrutura que lhe confere identidade específica e individual; b) essa nova célula humana começa imediatamente a agir como uma unidade individual, a qual, dadas as condições necessárias e suficientes, tende à gradual e completa expressão do plano organizado inscrito no seu próprio dote genético, mediante um complexo, contínuo e altamente coordenado processo de desenvolvimento; c) essa expressão se manifesta numa totalidade corpórea que se organiza autonomamente, isto é, por forças intrínsecas, até a formação de um organismo completo; e d) assim, a nova célula humana que se constitui na fusão dos pronúcleos materno e paterno representa a estrutura original de um novo homem, com o que começa seu próprio ciclo vital $(31,32)$. Os gametas masculino e feminino e os cromossomos presentes em seus pronúcleos, que são apenas agentes do processo reprodutivo, devem morrer enquanto tais para dar origem a um todo novo e completo, capaz

\footnotetext{
17 Zegers Hochschild F. Consideraciones médicas e implicancias ético legales de la reproducción asistida en Chile [Sitio en Internet] Disponible en: http://www.uchile.cl/bioetica/doc/ repasis.htm Acceso em out. 2002. Chorão MB. Concepção realista da personalidade jurídica e estatuto do nascituro. Revista brasileira de direito comparado 1999; Rio de Janeiro, Instituto de Direito Comparado Luso-Brasileiro; 17: 282. Em reunião plenária, realizada em 22 de fevereiro de 1987, a Congregação para a Doutrina da Fé, da Igreja Católica Apostólica Romana, aprovou instrução em que afirma que no zigoto, logo após a fertilização, já está constituída a identidade biológica de um novo indivíduo humano, definindo o zigoto como "a célula resultante da fusão dos núcleos dos dois gametas" (Ratzinger J. Congregação para a doutrina da fé. Instrução sobre o respeito à vida nascente e a dignidade da procriação. São Paulo: Paulinas; 1987: 21.)
} 
de converter-se em um homem ou em uma mulher. Em outras palavras, a cariogamia pode ser identificada com o processo de morte de dois genomas incompletos e de geração de um genoma completo. Três propriedades fundamentais decorrem do genoma formado com a cariogamia: a) a identidade especificamente humana do concepto, uma vez que seu genoma não deriva senão da fusão de dois genomas humanos; $b$ ) a identidade individual do concepto, porque seu genoma o distingue de todos os outros zigotos humanos; e c) a dotação de um plano-programa que garante ao concepto a plena potencialidade (não pura possibilidade) para a realização gradual de sua humanidade(32, p.130). O Conselho Português de Ética para as Ciências da Vida também delimita as fronteiras da teoria da cariogamia, acentuando que "certo é o princípio de que uma nova vida humana é marcada pela concepção, devendo entender-se por esta a (cariogamia), ou seja, a fusão dos dois pronúcleos (de origem materna e paterna) e não a penetração do espermatozóide no óvulo". E lembra que essa "distinção não é irrelevante, antes tem importância prática, porque, se aceita, permite a realização de experiências no óvulo, mesmo que penetrado pelo espermatozóide (p. ex., após a micromanipulação), dado que, na ausência de fusão dos pronúcleos, não se pode falar em desenvolvimento de um ser humano" 18 .

\section{Três teses que fundamentam a fragilidade da teoria do pré-embrião}

\subsection{O genoma humano é especificamente individual desde a concepção}

A teoria do pré-embrião defende que até o $14^{\circ}$ dia após a concepção humana não existe

\footnotetext{
18 "A vida humana é inviolável, estatui exemplarmente a Constituição da República Portuguesa no seu artigo 24. Sendo assim, e se se afigura impossível negar a existência de uma nova vida humana desde a (cariogamia), o concepto não poderá ser objeto de qualquer experimentação que conduza, ou possa conduzir, à sua destruição" (Relatório sobre a experimentação no embrião - 15/CNECV/95. Conselho Português de Ética para as Ciências da Vida. 4 out. 1995).
}

individualidade, considerando-se que o termo latino individuus é a tradução do termo grego atomos, que significa indivisível. Assim, indivíduo é aquele que não é passível de divisão e que, se dividido, morre ou se dissolve. Nesse sentido, havendo a potencialidade gemelar na concepção humana, não seria correto afirmar que desde então o homem dispõe de um genoma humano especificamente individual(33). A teoria da cariogamia, por seu turno, comprova que tal objeção somente teria valor científico caso se demonstrasse que a divisão do zigoto dissolve ou, de algum modo, aniquila sua unidade orgânica original; o que, como é sabido, não ocorre. Os dados da embriologia esclarecem que a separação dos blastômeros ou a divisão do embrião, desde que aconteça entre 60 horas e 15 dias após a fertilização, possibilita a formação de gêmeos monozigóticos ${ }^{19}$. No entanto, segundo Angelo Serra, em havendo a gemelidade monozigótica, há sempre um primeiro (primo) do qual se origina um segundo (secondo). Não se trata, ao invés, de um (uno) não definido que encerra em si, de modo confuso, um outro (un altro), tornado-se, em dado momento, dois $(d u e)^{20}$. Na mesma linha de raciocínio é de todo cabível perguntar: "se no futuro próximo for possível clonar um ser humano adulto a partir de suas células somáticas, significará isto a necessidade de se reconsiderar sua individualidade?"(13,p.1069)

\footnotetext{
${ }^{19}$ É bem verdade que a gemelidade ocorre mais comumente entre o terceiro e o oitavo dias depois da concepção e que as características do fenômeno deixam claro, também, que é possível ocorrer mais de uma subdivisão pós-zigótica, originando mais de dois indivíduos.

${ }^{20}$ Serra A. Chi o che cosa è l'embrione umano? I dati della scienza. In: Sgreccia E, Pietro Mldi, org. Bioetica ed educazione. Milano: Editrice La Scuola; 1997: 141. "Exibemse partes de uma lombriga, cada qual regenerando a sua cabeça e vivendo daí or diante como outros tantos indivíduos independentes; uma hidra cujos pedaços tornam-se outras tantas hidras novas; um ovo de ouriço do mar cujos fragmentos desenvolvem embriões completos: onde pois estava a individualidade do ovo? E da hidra ou do verme? É o que se costuma perguntar. Mas pelo fato de que haja agora várias individualidades não se segue que não tenha havido uma individualidade peculiar pouco antes" (Bergson H. A evolução criadora. Rio de Janeiro: Zahar; 1979: 23).
} 
Em outro contexto, a teoria do pré-embrião alinha argumentos também para negar ao concepto a qualidade de indivíduo em ato: "quando se afirma que uma coisa $\mathrm{X}$ é potencialmente uma coisa $\mathrm{Y}$, entende-se que $\mathrm{X}$ não é Y, mesmo se possui a capacidade intrínseca de se tornar Y"(33, p.43). Ora, a tese acerca da ausência de individualidade no concepto é contraditada pelos seus próprios argumentos. Esclareça-se: se o genoma humano especificamente individual $(\mathrm{X})$ possui a potencialidade da divisão (Y), entende-se que a individualidade $(\mathrm{X})$ não é divisibilidade (Y), mesmo se possui a capacidade intrínseca de se dividir. $\mathrm{O}$ fato de que o zigoto contém a informação genética necessária e suficiente para determinar - durante o período de totipotência das células decorrentes de sua clivagem - o desenvolvimento não apenas de uma mas, eventualmente, de individualidades gêmeas, significa que a cada um dos gêmeos monozigóticos deve ser reconhecida a plena individualidade desde sua constituição genética: o primeiro deles no momento mesmo da concepção e o outro, ou os demais, no momento da cisão gemelar ${ }^{21}$.

Para a teoria da cariogamia, a perda da totipotência no curso das primeiras fases do desenvolvimento humano não fornece ao zigoto a qualidade de autêntico indivíduo. Analogamente, a fusão de dois zigotos na fase de totipotência, da qual pode derivar uma só individualidade, é interpretada como a morte de um zigoto, terminado seu brevíssimo ciclo vital, sem que isto altere a individualidade já

\footnotetext{
21 "Pode ser certo que não necessariamente haja uma pessoa humana a partir da formação do genoma. No entanto, disto não se segue que não haja pessoa humana, já que poderia não existir apenas uma, mas duas pessoas humanas, com o que o estatuto do concepto antes das duas primeiras semanas após a concepção daria lugar a um duplo respeito. Assim, a existência de gêmeos monozigóticos reforça o critério da formação do genoma como o ponto de partida biológico da pessoa humana" (Martínez Barrera J. Los fundamentos de la bioética de H. Tristram Engelhardt. Sapientia 1997; 202: 314).
}

subsistente do outro zigoto 22 . Os adeptos da teoria do pré-embrião, por seu turno, também defendem que, antes de definidas as células que formarão o embrião propriamente dito, ou os embriões monozigóticos, e as células que se destinarão às estruturas extra-embrionárias, que servem às necessidades de seu desenvolvimento, não é possível falar em indivíduo humano em ato. Ora, o desenvolvimento embrionário é essencialmente um processo de crescimento e de progressiva complexidade de estrutura e de função. $\mathrm{O}$ crescimento, realizando-se através de mitoses juntamente com a produção de matrizes extraembrionárias, e a complexidade, resultando da morfogênese e da diferenciação, fazem desse conjunto celular um sistema orgânico. Um sistema orgânico, segundo Günter Rager, "precisamente se caracteriza porque o todo é mais do que a soma de suas partes"(34). Daí porque, conforme demonstra a teoria da cariogamia, despropositada é a intenção de querer apreender a individualidade humana dando-se ênfase a uma lógica meramente analítica (como o aparecimento da linha primitiva), já que seus resultados não denotam senão o descompromisso com a compreensão da totalidade e a ignorância da divisão biológica do trabalho ${ }^{23}$. Max Scheler, cuja doutrina alicerça o chamado pensamento forte, acentua que não é necessário um ser permanente que se conserve o mesmo na sucessão do tempo para assegurar "a identidade da pessoa individual". A identidade reside exclusivamente na direção qualitativa desse "puro tornar-se outro" na vida de um mesmo indivíduo. Desta maneira, care-

\footnotetext{
${ }^{22}$ Barberio Corsetti L, et alli. Per noi l'embrione è già un uomo. Associazione Medici Cattolici Italiani - Sezione di Ferrara [Sitio en Internet] Disponible en: http:// www.comune.ferrara.it/mm/amci/orizz01.htm. Acceso em out. 2002

${ }^{23}$ Ora, "o sistema nervoso nasce, como os demais sistemas, de uma divisão do trabalho. Ele não cria a função; ele apenas a eleva a grau mais alto de intensidade e precisão ao lhe dar a dupla forma de atividade reflexa e de atividade voluntária". Comparativamente, não se pode declarar um animal incapaz de nutrir-se por não ter estômago. Cf. Bergson H. A evolução criadora. Rio de Janeiro: Zahar; 1979: 103.
} 
ce de sentido pretender apreender a "pessoa individual" em suas vivências isoladas, porque ela realiza sua existência precisamente vivendo suas possíveis vivências(35).

\subsection{O genoma humano é unitário desde a concepção}

O genoma humano, em sua forma diplóide, consiste em aproximadamente três bilhões de pares de bases nitrogenadas organizados linearmente em 23 pares de cromossomos. Pelas estimativas atuais, o genoma humano contém 30.000 (trinta mil) a 40.000 (quarenta mil) genes. Desde a concepção o ser humano dispõe de um genoma humano unitário, isto é, que é idêntico ao do adulto que há de ser. Não existem diferenças na composição genética do concepto e do indivíduo adulto. Nenhuma outra informação genética é adicionada, nem subtraída, para que o concepto se desenvolva até a fase adulta. Porque toda a informação genética necessária para autocomandar o desenvolvimento do zigoto, do embrião, do feto, do recém-nascido, da criança, do adolescente e do adulto, está presente desde a concepção do ser humano (genoma humano), é possível afirmar que: a) existe identidade genética absoluta em todas as células somáticas do organismo humano e entre estas e a célula somática inicial, o zigoto; e b) o zigoto tem o projeto e a auto-suficiência para, interagindo com o ambiente, constituir um ser humano adulto $^{24}$. Não se deve esquecer, a este respeito, que o próprio relatório final do Warnock Committee, a que muitos se referem como o substrato científico da teoria do pré-embrião, expressamente afirma em seu capítulo 11 que a divisão do processo de desenvolvimento humano em espaços temporais é bastante crítica, já que, uma vez iniciado tal processo, não existe um estágio particular que seja mais importante que o outro; todos são parte de um processo contínuo e, se algum não se realiza em seu justo tempo e na seqüência exata, o desenvolvimento ulterior cessa. Logo, de um ponto de vista biológico, não se pode identificar um único estágio do desenvolvimento em que a vida humana não mereça proteção ${ }^{25}$. Daí porque, para a teoria da cariogamia, o concepto não é um ser humano em potência, em potência é apenas o desenvolvimento humano. Nesse particular, convém esclarecer a diferença substancial entre a mera possibilidade de converter-se em um ser humano e a capacidade atual de desenvolver-se, relativa a um ser humano que já existe e cujo potencial de desenvolvimento é intrínseco a ele mesmo. Em verdade, o potencial que pertence a um indivíduo humano em desenvolvimento está determinado pela sua própria natureza de indivíduo humano. Em outras palavras, "um ser humano, nas diversas etapas de seu desenvolvimento, não é, por sua natureza, um algo que se converte em alguém, senão que é alguém desde o início de seu desenvolvimento"(36).

O processo de desenvolvimento humano, que se inicia no estágio de zigoto, apresenta três características fundamentais: a) a coordenação, que se manifesta num processo integrado de atividades nos planos molecular e celular; b) a continuidade, que permite compreender a vida como uma unidade que se desdobra de um estágio mais simples para outro mais complexo num mesmo ciclo ininterrupto, pois qualquer interrupção caracteriza a patologia ou a morte; e c) a gradualidade, que evidencia a existência de uma regulação intrínseca, inscrita no próprio genoma, assegurando ao ser humano a aquisição de sua forma final(32, p.138-9). Ora, se a inserção de um indivíduo em uma dada

\footnotetext{
25 Department of Health and Social Security, 1984. Cf. Serra A. Chi o che cosa è l'embrione umano? I dati della scienza. In: Sgreccia E, Pietro Mldi, org. Bioetica ed educazione. Milano: Editrice La Scuola; 1997: 140.

${ }^{24}$ Cf. De Souza e Azevêdo EE. Aborto. In: Garrafa V, Ibiapina Ferreira Costa S, org. A bioética no século XXI. Brasília: UNB, 2000: 87-8. No mesmo sentido, Rager G. Embrion-hombrepersona. Acerca de la cuestion del comienzo de la vida personal. Cuadernos de bioetica Madrid 1997; VIII; 31: 1052.
} 
espécie é determinada precisamente pela informação genética contida em suas células, em se tratando da espécie humana o conjunto dessas informações firma-se no exato momento da fusão dos pronúcleos materno e paterno. Assim, a convicção de que o ser humano dispõe de um genoma unitário desde a concepção apenas reafirma a compreensão do ciclo vital como o desdobrar contínuo e gradual de uma totalidade coordenada. Com efeito, na idéia de duração fica evidente que é desprovida de sentido a distinção entre o "antes" e o "depois", pressuposta pela teoria do pré-embrião, já que em cada etapa da existência humana o todo se faz expressar potencialmente. Em passagens primorosas de sua obra filosófica, Henri Bergson ensina que "as propriedades vitais jamais estão inteiramente realizadas, mas sempre em vias de realização; são menos estados do que tendências. E uma tendência só obtém tudo a que visa se não for contrariada por outra tendência qualquer". Na análise da vida humana antes do nascimento pode-se constatar o rigor da lição acima declinada já que "o desenvolvimento do embrião é uma perpétua mudança de forma e quem queira observar todos os seus aspectos sucessivos há de perderse num infinito, como acontece quando se lida com uma continuidade"(2, p.22-85).

\subsection{A autonomia biológica existe desde a concepção}

Esta terceira tese está para além das objeções pontuais da teoria do pré-embrião. No entanto, é importante explicitá-la em apoio à teoria da cariogamia. Costuma-se afirmar que o concepto, nas entranhas maternas, não possui individualidade alguma, sendo apenas uma parte da mulher. Trata-se, em verdade, de ilação doutrinária decorrente da não compreensão da autonomia em sentido biológico. Robert Spaemann esclarece que, desde a concepção, existe um indivíduo da espécie humana, distinto do organismo da mãe, recorrendo ao processo contínuo de seu próprio desenvolvimento(37). A intimidade entre a mãe e o filho não implica perda da autonomia de um ou de outro ${ }^{26}$. Dada sua autonomia biológica para prover o próprio desenvolvimento, o concepto pode inclusive desencadear uma resposta antígeno-anticorpo no organismo materno. Um dos melhores exemplos desse fenômeno é a enfermidade hemolítica perinatal por incompatibilidade do grupo sangüíneo $\mathrm{Rh}$, quando a concepção de um indivíduo $\mathrm{Rh}$ positivo induz a formação de anticorpos na mãe $\mathrm{Rh}$ negativa, produzindo naquele uma substância química chamada bilirrubina(38). Ademais, não se deve esquecer que as técnicas de fertilização extracorpórea igualmente demonstram que o concepto tem autonomia para engendrar sua placenta e prover seu desenvolvimento até mesmo em úteros emprestados, isto é, tem autonomia de desenvolvimento independentemente da maternidade biológica. Não tem sentido algum distinguir, em um mesmo ser humano, a vida orgânica da vida humana, porque, desde quando há vida em sentido individual e unitário, se trata da vida de um homem(7, p.43). Nada se torna humano se já não o é desde então(39). Embora necessite do ventre materno para o desenvolvimento das primeiras etapas do seu ciclo vital, não se deve subestimar que a necessidade da mãe para o novo ser humano, e não apenas dela, permanece com grande intensidade ainda nos primeiros anos após o nascimento e, de maneiras muito diversas, ao longo de toda a vida. Ao contrário de outros mamíferos, o homem nasce necessitando dos cuidados constantes de outro homem para não sucumbir(40). Nesse sentido, "o homem é o animal que nasce com menor autonomia na escala zoológica" $(38$, p.220). As relações com

\footnotetext{
26 "O amor é interdependência. Não se pode amar na dependência, nem na independência. $\mathrm{O}$ amor de dependência é mesquinho, dominador, reduz-se a uma letal comodidade. Amar independentemente é ignorar o outro, é ficar alienado no próprio desejo. Uma independência que termina em indiferença. $\mathrm{O}$ amor de interdependência é o amor de plenitude, medular com todas as letras. A sincronia que permite conviver com o outro para produzir juntos a diferença, increver o novo na temporalidade" (Warat LA. A ciência jurídica e seus dois maridos. Santa Cruz do Sul: Edunisc; 2000: 116).
} 
outras pessoas além da mãe, que ganha espaço da primeira infância em diante, mediante uma variedade de formas, também ajudam o ser humano a exprimir mais completamente suas potencialidades. Tudo isto, entretanto, pressupõe a presença de uma individualidade humana - não a constitui enquanto tal.

\section{Considerações finais}

Importante implicação do reencontro do direito com a ética, que favorece a compreensão do fenômeno humano, é a convicção de que, entre indivíduo e pessoa, não cabe a distinctio per oppositionem, pois ambos se acham reunidos no mesmo homem, como duas qualificações, como duas forças. Com efeito, a unidade original entre os conhecimentos sobre o início da existência humana e a compreensão ética da qualidade de pessoa encontra fundamento em duas razões interdependentes: $1^{\mathrm{a}}$ ) o indivíduo humano, inserido no âmbito da humanidade, somente possui significado vital na realidade ontológica da pessoa; e $2^{\mathrm{a}}$ ) a pessoa humana, em sua singularidade existencial e enquanto ser em relação, não existe senão imersa em uma individualidade biológica. Cada indivíduo humano é expressão simultânea de si mesmo e da humanidade, razão pela qual a pessoa, que se encontra na essência de toda individualidade humana, traz consigo esse chamado que aparentemente se encontra para além de suas fronteiras: $o$ abrir-se para os outros indivíduos humanos. Outra importante implicação do reencontro do direito com a ética diz respeito à constatação da incapacidade da tecnociência para a compreensão do fenômeno humano. Como o conhecimento vulgar, a tecnociência cisma em reter do que investiga somente o aspecto repetição. Se o todo é pura criação, ela encontra meios de torná-lo artificial, decompondo-o em aspectos que sejam quase a reprodução do passado. A essência desse tipo de explicação, inicialmente denominada mecanicista, consiste em considerar o futuro e o passado como calculáveis em função do presente. Nega-se a duração enquanto traço de união. Segundo Henri Bergson, necessária então se faz a compreensão de que vida implica uma continuação real do passado pelo presente, isto é, uma duração em que o passado, sempre em marcha, se enche sem cessar de um presente absolutamente novo. Em outras palavras, o conhecimento da vida necessariamente recai sobre o próprio intervalo de duração, sendo a tecnociência, preocupada apenas com as extremidades, adequada para o conhecimento de sistemas artificiais. Logo, a explicação mecanicista é imprópria para tratar do fenômeno humano porque "a vida não procede por associação e adição de elementos, mas por dissociação e desdobramento"(2, p.22-85). Pode-se fechar este estudo asseverando que as implicações do reencontro do direito com a ética, desde que alicercem um pensamento forte no âmbito bioético, legitimam um uso responsável da expressão biodireito, para identificar a maneira mais igualitária de entender e empregar o jurídico. Se o direito existe para a proteção e promoção da dignidade da pessoa humana, e se todo indivíduo humano é pessoa, conforme as diretrizes bioéticas assinaladas, inadmissível é o uso da expressão biodireito senão para a tutela integral da vida, desde a concepção, ainda que extra-uterina, até a fase adulta. Caso assim não seja, o que muito se lastima, o uso da expressão biodireito não passará de um modismo, um rótulo para mais uma variante do pensamento fraco. 


\section{Referencias}

1. D’Agostino F. Bioetica nella prospettiva della filosofia del diritto. Torino: G. Giappichelli Editore; 1998: 187.

2. Bergson H. A evolução criadora. Rio de Janeiro: Zahar; 1979: 14, 147-8.

3. Piettre B. Filosofia e ciência do tempo. Bauru: EDUSC, 1997: 45-6.

4. De Souza Santos B. Uma concepção multicultural de direitos humanos. Revista Lua Nova São Paulo, CEDEC - Centro de Estudos de Cultura Contemporânea 1997; 39: 122.

5. Espinoza E. Sullo statuto giuridico del concepito. Il diritto di famiglia e delle persone. Milano 1994; anno XXIII: 382.

6. Singer P. Ética prática. São Paulo: Martins Fontes; 1993: 149.

7. Sgreccia E, Di Pietro ML. Bioetica e persona. En: Sgreccia E, Di Pietro ML, org. Bioetica ed educazione. Milano: Editrice La Scuola; 1997: 36-41.

8. Andorno R. El derecho argentino ante los riesgos de cosificación de la persona en la fecundación in vitro. En: Andorno R, org. El derecho frente a la procreación artificial. Buenos Aires: Editorial Ábaco de Rodolfo De Palma; 1997: 62.

9. João Paulo II. Evangelium Vitae: 6 [Sitio en Internet]. Disponible en: http://www.vatican.va/ holy_father/john_paul_ii/encyclicals/documents/hf_jp-ii_enc_25031995_evangelium-vitae_po.html Acceso en agosto. 2002.

10. Schooyans M. Dominando a vida, manipulando os homens. São Paulo: Ibrasa; 1993: 48-9.

11. Alsina JB. Bioetica y responsabilidad. En: Alterini AA, et al, org. La responsabilidad. (Homenaje al profesor Isidoro H. Goldenberg.) Buenos Aires: Abeledo-Perrot, 1996: 42.

12. Chiesa PJM. El estatuto biológico-moral. En: Andorno R, et al, org. El derecho frente a la procreación artificial. Buenos Aires: Editorial Ábaco de Rodolfo De Palma; 1997: 45.

13. Serani Merlo A. El estatuto antropológico y ético del embrión humano. Cuadernos de Bioética. Madrid 1997; VIII; 31: 1071-3.

14. Ciccone L. La FIVET, una tragica sperimentazione sull'uomo. Il diritto di famiglia e delle persone. Milano 1987; anno XVI: 1000.

15. Mantovani F. Le possibilità, i rischi e i limiti delle manipolazioni genetiche e delle tecniche bio-mediche moderne. Fórum internacional de direito penal comparado. Salvador, Tribunal de Justiça da Bahia; 8, 9 e 10 mar. 1989: 232. 
16. Mathieu B. La vie en droit constitutionnel comparé: éléments de réflexion sur un droit incertain. Revue internationale de droit comparé. Société de Législation Comparée. Paris 1998; 4 (1): 1037

17. Cordeiro Leite dos Santos MC. Imaculada concepção. Nascendo in vitro e morrendo in machina. São Paulo: Acadêmica; 1993: 105-17.

18. Rapporto W. Quali frontieri per la vita? Milano: Avvenire; 1985: 93.

19. Folscheid D. L'embryon ou notre docte ignorance. En: Le Mintier BF, org. L'embryon humain. Approche multidisciplinaire. Paris: Economica; 1996: 25.

20. Renard JP. L'embryon in vitro. En: Le Mintier BF, org. L'embryon humain. Approche multidisciplinaire. Paris: Economica; 1996: 6-7

21. Lejeune J. Genética humana e espírito. Brasília: Centro Gráfico do Senado Federal; 1992: 14-5.

22. Warnock M. Os usos da filosofia. Campinas: Papirus; 1994: 51.

23. Teilhard de Chardin P. O fenómeno humano. Porto: Tavares Martins; 1970: 235.

24. Berlinguer G. Questões de vida: ética, ciência, saúde. Salvador: APCE-HUCITEC-CEBES; 1993: 42.

25. Ford N. Quando comincio io? Il concepimento nella storia, nella filosofia e nella scienza. Milano: Baldini \& Castoldi; 1997: 243-67.

26. Lacadena JR. Reproducciòn humana. Genética y bioética [Sitio en Internet] Disponible en: http:// www.cnice.mecd.es/tematicas/genetica/index.html Acceso en agosto. 2002.

27. Contro la sperimentazione sugli embrioni umani. Documento N. ${ }^{\circ} 1$ Centro di Bioetica. Università Cattolica del Sacro Cuore; 1996

28. Martínez A. La Infertilidad y sus tratamientos. Aspectos médicos. En: Andorno R, et al, org. El derecho frente a la procreación artificial. Buenos Aires: Editorial Ábaco de Rodolfo De Palma; 1997: 25-6.

29. Andorno R. Bioética y dignidad de la persona. Madrid: Tecnos; 1998: 94.

30. Comitato Direttivo del Centro di bioetica. Identità e statuto dell'embrione umano. Medicina e Morale Roma, (Supplemento 4) 1989: 1.

31. Serra A. Per un'analisi integrata dello 'status' dell'embrione umano. Alcuni dati della genetica e dell'embriologia. En: Biolo S, org. Nascita e morte dell'uomo. Problemi filosofici e scientifici della bioetica. Génova: Marietti; 1993: 58.

32. Serra A. Chi o che cosa è l'embrione umano? I dati della scienza. En: Sgreccia E, Pietro Mldi, org. Bioetica ed educazione. Milano: Editrice La Scuola; 1997: 129.

33. Mori M. A moralidade do aborto. Brasilia: UnB; 1997: 52. 
Bioética e biodireito: as implicações de um reencontro - R. Pereira e Silva

34. Rager G. Embrión-hombre-persona. Acerca de la cuestión del comienzo de la vida personal. Cuadernos de bioética Madrid 1997; VIII; 31: 1048.

35. Scheler M. Ética. Nuevo ensayo de fundamentación de un personalismo ético. T. II. Buenos Aires: Revista de Occidente; 1948: 175-6.

36. Honnefelder L. Naturaleza y status del embrión. Aspectos filosóficos. Cuadernos de bioetica Madrid 1997; VIII; 31: 1040-2.

37. Spaemann R. ¿Son todos los hombres personas? Cuadernos de Bioética Madrid 1997; VIII; 31: 1029-31

38. Vila-Coro Barrachina MD. Introducción a la biojurídica. Madrid: Universidad Complutense; 1995: 50.

39. Ratzinger J. Congregação para a doutrina da fé. Instrução sobre o respeito à vida nascente e a dignidade da procriação. São Paulo: Paulinas; 1987: 20.

40. De Souza e Azevêdo EE. O direito de vir a ser após o nascimento. Porto Alegre: Edipucrs; 2000: 68. 